\title{
RELATIVE RISK OF CORONAVIRUS DISEASE (COVID-19) IN SOUTH SULAWESI PROVINCE, INDONESIA: BAYESIAN SPATIAL MODELING
}

\author{
Aswi Aswi, Andi Mauliyana, Muhammad Arif Tiro, Muhammad Nadjib Bustan \\ Statistics Department, Universitas Negeri Makassar
}

e-mail: aswi@unm.ac.id

\section{DOI:10.14710/medstat.14.2.158-169}

\section{Article Info: \\ Received: 12 October 2021 \\ Accepted: 12 December 2021 \\ Available Online: 11 Januari 2022}

Keywords:

Covid-19; relative risk; bayesian CAR localised

\begin{abstract}
The Covid-19 has exploded in the world since late 2019. South Sulawesi Province has the highest number of Covid-19 cases outside Java Island in Indonesia. This paper aims to determine the most suitable Bayesian spatial conditional autoregressive (CAR) localised models in modeling the relative risk (RR) of Covid-19 in South Sulawesi Province, Indonesia. Bayesian spatial CAR localised models with different hyperpriors were performed adopting a Poisson distribution for the confirmed Covid-19 counts to examine the grouping of Covid-19 cases. All confirmed cases of Covid-19 (19 March 2020-18 February 2021) for each district were included. Overall, Bayesian CAR localised model with $\mathrm{G}=5$ with a hyperprior IG $(1,0.1)$ is the preferred model to estimate the RR based on the two criteria used. Makassar and Toraja Utara have the highest and the lowest RR, respectively. The group formed in the localised model is influenced by the magnitude of the mean and variance in the count data between areas. Using suitable Bayesian spatial CAR localised models enables the identification of high-risk areas of Covid-19 cases. This localised model could be applied in other case studies.
\end{abstract}

\section{INTRODUCTION}

Human-to-human transmission of the coronavirus disease 2019 (Covid-19) has exploded in the world since late 2019 (Shereen et al., 2020). The disease is spreading exponentially worldwide and has been felt in at least 219 countries with 108,246,992 confirmed cases with 2,386,717 deaths by 16 February 2021 (WHO, 2021). Indonesia reported the first case of Covid-19 on March 2, 2020. The Government of the Republic of Indonesia has reported 1,210,703 people who were confirmed with Covid-19 in Indonesia by 16 February 2021. A total of 32,936 deaths were reported related to Covid-19 (WHO, 2021). South Sulawesi Province is an area that has the highest number of Covid-19 cases outside Java Island in Indonesia (CNN, 2020). From 19 March 2020 to 18 February 2021, as many as 53,348 confirmed cases of Covid-19 were reported, with details of 48,524 recovered and 815 people died (Dinkes, 2021).

Research on Covid-19 in Indonesia has been conducted by several researchers. One of the studies used a Suspected-Exposed-Infected-Recovered (SEIR) mathematical model which involved vaccination and isolation factors (Annas et al., 2020). Their results 
recommend that a vaccine can accelerate the healing of Covid-19. Furthermore, one of the Covid-19 studies conducted in South Sulawesi province was to use the Richards time series model (Zuhairoh \& Rosadi, 2020). The Susceptible - Infected - Recovered (SIR) mathematical model approach has also been used in predicting cases of Covid-19 in South Sumatra, Indonesia (Yeni et al., 2020). Another SIR model has been used to predict Covid19 cases in East Kalimantan and Samarinda (Sifriyani \& Dedi, 2020). However, there appears to have been limited studies considering Bayesian spatial models in modelling Covid-19.

A range of Bayesian spatial models has been investigated such as Conditional Autoregressive (CAR) Besag-York-Mollié (BYM), Leroux, and localised models (Aswi et al., 2020a) The performance of these models has been investigated through both a simulation study and a case study on dengue fever. They found that, overall, the CAR Leroux model performed better based on the simulation study. However, the localised model performed better and is recommended when the count data and variance are relatively large contrast over areas. A Bayesian spatial CAR localised has also been used to estimate the health effects of air pollution (Lee et al., 2014).

Recently, research on Covid-19 modeling has been considered the spatial effects and the Bayesian method (Goldstein et al., 2021; Konstantinoudis et al., 2021). A study used a Bayesian model in modeling Covid-19 cases in Lebanon but only considered the temporal effect (Samer, 2020). However, to our knowledge, using Bayesian spatial CAR localised in modeling Covid-19 cases has not been explored yet. The appealing features of CAR localised models are that the model can distinguish between groups of areas that have high relative risk and low relative risk. Furthermore, this localised model can also identify outliers (Aswi et al., 2020a). As the count data and variance of confirmed Covid-19 cases in South Sulawesi Province are relatively large contrast over areas, it is reasonable to consider the Bayesian Spatial CAR localised models in analysing the relative risk of Covid19 cases in this study. This paper aims to determine the most suitable Bayesian spatial CAR localised models in estimating the relative risk of Covid-19 in South Sulawesi Province, Indonesia.

\section{LITERATURE REVIEW}

\subsection{Spatial Autocorrelation}

The most common indicator used to measure spatial dependence is Moran's $I$. It was proposed by statistician Patrick AP Moran in 1950 (Moran, 1950). Moran's I statistics is defined as follows:

$$
I=\frac{n \sum_{i=1}^{n} \sum_{j=1}^{n} \omega_{i j}\left(X_{i}-\bar{X}\right)\left(X_{j}-\bar{X}\right)}{\sum_{i=1}^{n} \sum_{j=1}^{n} \omega_{i j}\left(X_{i}-\bar{X}\right)^{2}}
$$

$n$ is the number of areas, $X_{i}$ and $X_{j}$ is the observed value in the areas $i$ and $j, \bar{X}$ is the average of the $X$ values over the $n$ locations or area, $\omega_{i j}$ is the spatial weighted matrix (measures the spatial dependence between areas $i$ and $j$ ).

\subsection{Spatial Weight Matrix}

The most commonly spatial weight matrix for areal data is the binary spatial matrix and first-order adjacency weights which are defined as: $\omega_{i j}=1$ if areas $i$ and $j$ are neighbour and $\omega_{i j}=0$ otherwise. There are three forms of spatial matrices namely rook contiguity, 
bishop contiguity, and queen contiguity. The visual explanation of these spatial weight matrixes can be seen in some literature (Aswi et al., 2021; Oyana \& Margai, 2015). The commonly binary spatial matrix, first-order neighbourhod weights matrix appears as a better choice for achieving a better model fit for implementing spatial smoothing (Duncan et al., 2017). Furthermore, the 'queen' contiguity improved the model fit (Getis \& Aldstadt, 2004). Therefore, the Queen contiguity weight structure was used in this paper.

\subsection{Relative Risk (RR)}

Standardised Incidence Ratio (SIR) is the ratio of the number of cases of Covid-19 $\left(y_{i}\right)$ to the expected value of a case of Covid-19 in a certain area $\left(E_{i}\right)$ which is formulated as follows:

$$
S I R_{i}=\frac{y_{i}}{E_{i}}
$$

The expected value of the number of disease cases can be calculated as follows:

$$
E_{i}=\frac{\sum_{i} y_{i}}{\sum_{i} n_{i}} n_{i}
$$

where $n_{i}$ is the number of populations in area $i$.

To obtain the risk estimates, Bayesian disease models are preferred rather than SIRs as they enable to include information from neighbouring regions by using prior distribution and enable to incorporate covariates to improve local estimates.

\subsection{Bayesian Analysis}

Unlike classical statistics, Bayesian statistics assume that all unknown parameters are considered random variables. In a Bayesian analysis, the posterior distribution is proportional to the product of the prior distribution (the information available to the researcher without the data) and the likelihood (Austin et al., 2002).

\subsection{Model Comparison}

To measure how well the observed data fit the model, goodness-of-fit statistics are commonly used. A number of goodness-of-fit measures have been proposed such as Akaike information criterion (AIC), Bayesian information criterion (BIC), deviance information criterion (DIC) (Lawson, 2013). DIC (Spiegelhalter et al., 2002) is commonly used for the comparison of Bayesian hierarchical models especially when the random effects are included in the model. The formula of DIC is given as follows:

$$
D I C=\overline{D(\theta)}+p_{D}=D(\bar{\theta})+2 p_{D}
$$

where

$$
\overline{D(\theta)} \text { is the posterior mean deviance of the model; }
$$

$p_{D}$ is the effective number of parameters which is defined as the mean deviance minus the deviance of the means and it is written as follows:

$$
p_{D}=\overline{D(\theta)}-D(\bar{\theta})
$$

and

$$
D(\theta)=-2[\log p(y \mid \theta)]+2 \log [f(y)]
$$


The DIC performs well for exponential family models but it may not work well for mixture models due to its dependence on the parametrization and focus of a model. Furthermore, DIC is not fully Bayesian and the effective number of parameters could have negative estimates. DIC may not work for singular models.

Watanabe-Akaike information criterion (WAIC) (Watanabe, 2010) could be seen as an advancement on the DIC for Bayesian models. The WAIC is fully Bayesian, and invariant to parameterisation. WAIC also works for singular models. Even though WAIC has many advantages over DIC, it is less used in practice as it requires additional computational steps (Vehtari et al., 2017).

\section{MATERIAL AND METHOD}

\subsection{Study Area}

South Sulawesi Province consists of 21 districts and 3 cities (Makassar, Pare-Pare, and Palopo) with a population of approximately 8,851,240 (4,524,831 females and 4,326,409 males). The province's area is $45,764.53 \mathrm{~km}^{2}$ with a population ranging from 135,624 to 1,526,677 in 2019. Luwu Utara has the largest district with an area of $7502.58 \mathrm{~km}^{2}$ and ParePare is the smallest district with an area of $99.33 \mathrm{~km}^{2}$. The population density of South Sulawesi Province was 193 people per km² in 2019 (Badan Pusat Statistik, 2020).

\subsection{Covid-19 Data}

The data used in this study is data on the number of confirmed cases of Covid-19 from 19 March 2020 to 18 February 2021 for each district in South Sulawesi Province which consists of 24 districts/cities. Data on the number of confirmed cases of Covid-19 is obtained from the official website of the South Sulawesi Provincial Health Office (https://covid19.sulselprov.go.id/data) (Dinkes, 2021) while data on the population in each district is obtained from the Badan Pusat Statistik (Badan Pusat Statistik, 2020).

\subsection{Model Formulation}

The Bayesian spatial CAR localised model proposed by Lee and Saran (Lee \& Sarran, 2015) was used to examine the grouping of Covid-19 cases across South Sulawesi Province. This model enables neighbourhood random effects to differ across the geographic area. The areas are partitioned into maximum $G$ groups and include a group-specific mean in the model. The confirmed Covid-19 counts were modelled adopting a Poisson distribution. This Poisson distribution is the most commonly used in published papers (Aswi et al., 2019) for disease mapping as the number of diseases is discrete and rare relative to the number of population. The model is written as follows:

$$
\begin{aligned}
& y_{i} \sim \text { Poisson }\left(E_{i} \theta_{i}\right) \text { for } i=1,2,3, \ldots, 24 \text { areas } \\
& \log \left(\theta_{i}\right)=\alpha+u_{i}+\lambda z_{i}
\end{aligned}
$$

where $y_{i}$ is the observed number of confirmed Covid-19 cases in the $i^{\text {th }}$ area. $E_{i}$ is the expected counts in each area which are calculated as the overall incidence rate for the entire area multiplied by the population at risk in each area.

$\theta_{i}$ is the relative risk in the $i^{\text {th }}$ area, and $\alpha$ is the overall level of relative risk. The spatial random effect $\left(u_{i}\right)$ is modelled by a conditional autoregressive (CAR) prior as follows: 


$$
\left(u_{i} \mid u_{j}, i \neq j, \tau_{u}^{2}\right) \sim N\left(\frac{\sum_{j} u_{j} \omega_{i j}}{\sum_{j} \omega_{i j}}, \frac{\tau_{u}^{2}}{\sum_{j} \omega_{i j}}\right)
$$

where weight matrix $\omega_{i j}=1$ if areas $i, j$ are categorised as neighbours and $\omega_{i j}=0$ otherwise. The hyperpriors used for $\tau_{u}^{2}$ were Inverse-Gamma (IG) namely IG $(1,0.01)$ as the default prior of CARBayes (Lee, 2013); IG (1, 0.1); IG (0.5, 0.05) and IG (0.1, 0.01). Group G has its own form of intercept, namely $\lambda_{1}<\lambda_{2}<\ldots<\lambda_{\mathrm{G}}$. Prior $\lambda_{\mathrm{j}} \sim \operatorname{Uniform}\left(\lambda_{\mathrm{j}-1}, \lambda_{\mathrm{j}+1}\right)$ for $j=1$, $2, \ldots, G$, where $\lambda_{0}=-\infty$ and $\lambda_{G+1}=+\infty$. A variable $Z_{i}$ assigns the allocation of the $i^{\text {th }}$ area to a group,

$$
f\left(Z_{i}\right)=\frac{\exp \left(-\delta\left(Z_{i}-G^{*}\right)^{2}\right)}{\sum_{r=1}^{G} \exp \left(-\delta\left(r-G^{*}\right)^{2}\right)}
$$

where $\delta \sim \operatorname{Uniform}(1,10) ; G^{*}=\frac{\mathrm{G}+1}{2}$ if $\mathrm{G}$ is odd and $G^{*}=\frac{\mathrm{G}}{2}$ if $\mathrm{G}$ is even. $G$ value is fixed and it is suggested to set $\mathrm{G}$ to be a small and odd number (Lee \& Sarran, 2015).

A set of model formulations to examine the most appropriate spatial priors were used. Different spatial CAR localised models allowing a maximum of two $(G=2)$, three $(G=3)$, four $(G=4)$, and five $(G=5)$ groups were compared with different priors. These values of $\mathrm{G}$ were chosen as it is suggested to choose a small odd number (Lee and Sarran, 2015). Larger values of $G$ are not recommended because of the small number of areas.

Model parameters were estimated using the CARBayes package version 5.2 in $\mathrm{R}$ software version 3.6.1 (R Core Team, 2019). Markov Chain Monte Carlo (MCMC) was used for computation. Posterior quantities for parameters were based on 20,000 iterations with 12,000 MCMC samples collected after a burn-in of 8,000 samples. MCMC convergence was checked using visualization of MCMC trace and density plots. The selection of the best model is based on Deviance Information Criteria (DIC) and Watanabe Akaike Information Criteria (WAIC). The smaller value of DIC and WAIC is a better fit.

A sensitivity analysis was also performed to investigate how the priors affect the posterior estimation. Four distinct of the prior on the variance terms were used namely, IG $(1,0.01)$ as the default hyperprior in CARBayes, IG $(1,0.1), \operatorname{IG}(0.5,0.05)$, and $\operatorname{IG}(0.1,0.01)$. $\mathrm{R}$ code used to model the relative risk of confirmed Covid-19 counts are available upon request. The inverse-gamma (IG) distribution is a natural choice for a prior because it is a conjugate prior for the variance of the normal distribution (Congdon, 2020).

\section{RESULTS AND DISCUSSION}

A descriptive analysis of the number of confirmed Covid-19 cases in South Sulawesi Province from 19 March 2020 to 18 February 2021 depicts that a total of 53,025 confirmed Covid-19 cases were identified with a median (975.5), mean (2209.4), and variance $(27,977,408)$ respectively. Makassar city has the highest number of confirmed cases with 26,658 cases followed by Gowa with 4,790 cases, while Toraja Utara has the lowest number of confirmed Covid-19 cases with 206 cases.

The number of populations in South Sulawesi in 2019 is approximately 8,851,240. Makassar city has the highest population with 1,526,677 followed by Gowa with 772,684 while Selayar has the lowest number of populations with 135,624. The number of confirmed Covid-19 cases, the number of populations, and population density are given in Table Sl in the Online Appendix. 
The results of the Bayesian CAR localised model with $\mathrm{G}=2, \mathrm{G}=3, \mathrm{G}=4$, and $\mathrm{G}=$ 5 with four different hyperprior $\tau_{u}^{2}$ are given in Table 1 . Based on Table 1, it can be seen that the localised model with $\mathrm{G}=5$ with hyperprior IG $(1,0.1)$ has the lowest DIC (260.47) and WAIC (259.67) which each group G1, G2, G3, G4, and G5 has areas included, namely 2, 6, 9, 6, and 1 areas, respectively. The second-lowest DIC (261.17) and WAIC (261.63) is a localised model with $\mathrm{G}=5$ with hyperprior IG $(1,0.01)$ which each group has the same areas assigned with hyperprior IG $(1,0.1)$. In general, the best model to describe the relative risk of confirmed Covid-19 cases is a CAR localised model with $\mathrm{G}=5$ with a hyperprior IG (1, 0.1 ) based on the two criteria used.

Table 1. DIC, WAIC, and the Number of Areas Included in The Group for Each Localised Model With Different Hyperprior.

\begin{tabular}{|c|c|c|c|c|c|c|c|c|}
\hline \multirow{2}{*}{ Model } & \multirow{2}{*}{ Hyperprior $\left(\tau_{u}^{2}\right)$} & \multirow{2}{*}{ DIC } & \multirow{2}{*}{ WAIC } & \multicolumn{5}{|c|}{ Number of Areas in the Group } \\
\hline & & & & G1 & G2 & G3 & G4 & G5 \\
\hline \multirow{4}{*}{$\begin{array}{l}\text { Localised } \\
\mathrm{G}=2\end{array}$} & Inverse-Gamma $(1,0.01)$ & 270.68 & 288.48 & 9 & 15 & & & \\
\hline & Inverse-Gamma $(1,0.1)$ & 270.06 & 284.70 & 9 & 15 & & & \\
\hline & Inverse-Gamma $(0.5,0.05)$ & 270.79 & 288.99 & 9 & 15 & & & \\
\hline & Inverse Gamma $(0.1,0.01)$ & 269.90 & 282.04 & 9 & 15 & & & \\
\hline \multirow{4}{*}{$\begin{array}{l}\text { Localised } \\
\mathrm{G}=3\end{array}$} & Inverse-Gamma $(1,0.01)$ & 276.77 & 325.02 & 8 & 12 & 4 & & \\
\hline & Inverse-Gamma $(1,0.1)$ & 282.77 & 399.52 & 8 & 13 & 3 & & \\
\hline & Inverse-Gamma $(0.5,0.05)$ & 276.98 & 327.53 & 8 & 12 & 4 & & \\
\hline & Inverse Gamma $(0.1,0.01)$ & 284.33 & 420.06 & 8 & 13 & 3 & & \\
\hline \multirow{4}{*}{$\begin{array}{l}\text { Localised } \\
\mathrm{G}=4\end{array}$} & Inverse-Gamma $(1,0.01)$ & 278.15 & 347.08 & 2 & 6 & 11 & 5 & \\
\hline & Inverse-Gamma $(1,0.1)$ & 278.16 & 327.94 & 2 & 6 & 11 & 5 & \\
\hline & Inverse-Gamma $(0.5,0.05)$ & 276.23 & 323.12 & 2 & 6 & 11 & 5 & \\
\hline & Inverse Gamma $(0.1,0.01)$ & 276.84 & 326.91 & 2 & 6 & 11 & 5 & \\
\hline Localised & Inverse-Gamma $(1,0.01)$ & 261.17 & 261.63 & 2 & 6 & 9 & 6 & 1 \\
\hline \multirow[t]{3}{*}{$\mathrm{G}=5$} & Inverse-Gamma $(1,0.1)$ & 260.47 & 259.67 & 2 & 6 & 9 & 6 & 1 \\
\hline & Inverse-Gamma $(0.5,0.05)$ & 262.05 & 262.09 & 2 & 6 & 9 & 6 & 1 \\
\hline & Inverse Gamma $(0.1,0.01)$ & 261.35 & 261.62 & 2 & 6 & 9 & 6 & 1 \\
\hline
\end{tabular}

The number of confirmed Covid-19 cases, the relative risk (RR) value, and the grouping structure (localised structure LS) in each district based on the preferred model, namely the localised model with $\mathrm{G}=5$ with hyperprior $\mathrm{IG}(1,0.1)$ were given in Table 2 .

Table 2. The Number of Confirmed Covid-19 Cases, Relative Risk, and LS Using The Localised $\mathrm{G}=3$ Model With A Hyperprior IG $(1,0.1)$.

\begin{tabular}{lccc}
\hline Districts & $\begin{array}{c}\text { Number of Confirmed } \\
\text { Covid-19 Cases }\end{array}$ & $\begin{array}{c}\text { Relative } \\
\text { Risk }\end{array}$ & LS \\
\hline Makassar & 26658 & 2.91 & 5 \\
Luwu Timur & 2401 & 1.33 & 4 \\
Pare-Pare & 1121 & 1.28 & 4 \\
Palopo & 1238 & 1.11 & 4 \\
Gowa & 4790 & 1.03 & 4 \\
Maros & 1975 & 0.93 & 4 \\
Sinjai & 1307 & 0.89 & 4 \\
Barru & 788 & 0.75 & 3 \\
Soppeng & 980 & 0.72 & 3 \\
Bantaeng & 739 & 0.65 & 3
\end{tabular}




\begin{tabular}{lrll} 
Jeneponto & 1406 & 0.64 & 3 \\
Luwu Utara & 1200 & 0.64 & 3 \\
Pangkep & 1202 & 0.59 & 3 \\
Selayar & 441 & 0.54 & 3 \\
Takalar & 969 & 0.54 & 3 \\
Sidrap & 881 & 0.48 & 3 \\
Pinrang & 839 & 0.37 & 2 \\
Wajo & 755 & 0.31 & 2 \\
Bulukumba & 750 & 0.29 & 2 \\
Bone & 1270 & 0.27 & 2 \\
Luwu & 592 & 0.27 & 2 \\
Enrekang & 289 & 0.23 & 2 \\
Toraja & 228 & 0.16 & 1 \\
Toraja Utara & 206 & 0.15 & 1 \\
\hline
\end{tabular}

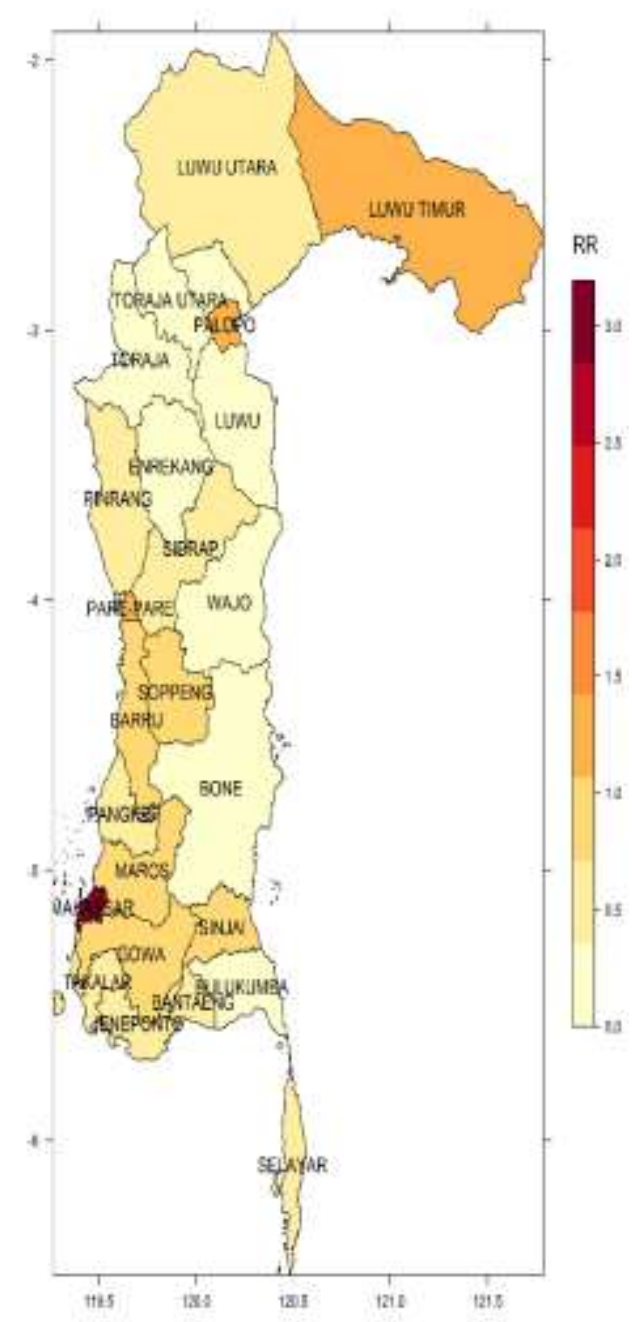

Figure 1. The Relative Risk of Confirmed Covid-19 Cases for Each District in South Sulawesi Province 
Based on Table 1 and Table 2, it can be seen that the number of areas included in the first group (G1) is 2, namely Toraja Utara and Toraja with relative risk (RR) values of 0.15 and 0.16 respectively. The number of areas included in the fifth group (G5) is only one, namely Makassar, with the relative risk values of 2.91. It can be concluded that Makassar has the highest relative risk of confirmed Covid-19 (2.91) followed by Luwu Timur (1.33) and Pare-Pare (1.28), while Toraja Utara (0.15) has the lowest relative risk of confirmed Covid-19 followed by Toraja (0.16). A visualization of the relative risk and grouping structure is presented in Figs 1 and 2 respectively.

Bayesian spatial CAR localised models with different hyperpriors especially for the variance hyperparameters have been compared. Our results depict that the localised model with $\mathrm{G}=5$ with hyperprior IG $(1,0.1)$ has the lowest DIC and WAIC, and it has formed 5 groups. The DIC and WAIC values for the localised model with hyperprior IG $(1,0.1)$ are indiscernible for the localised model with $G=5$ with hyperprior IG $(1,0.01)$. The most appropriate model to estimate the relative risk of confirmed Covid-19 cases based on the two metrics is the localised model with $G=5$ with a hyperprior $\operatorname{IG}(1,0.1)$. This is in line with the previous research recommending the $G$ to be small and odd (Lee \& Sarran, 2015).

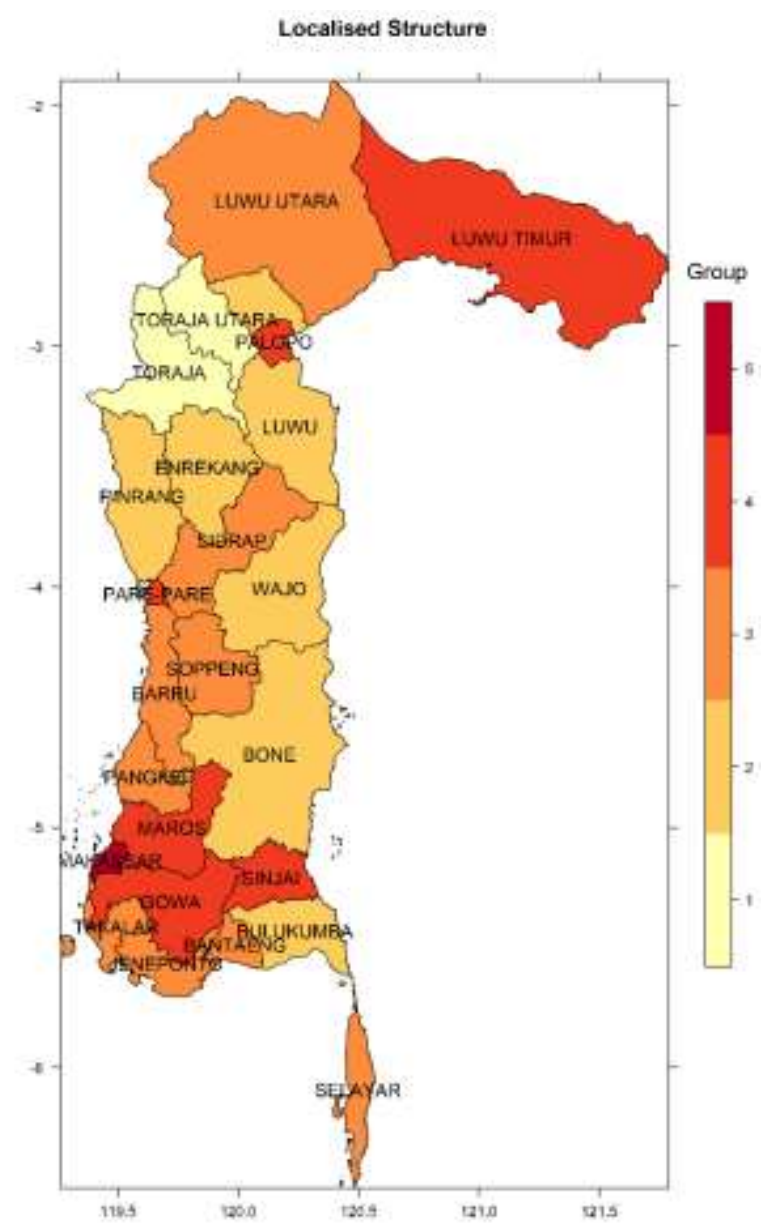

Figure 2. The Grouping Structure of The Preferred Localised Model

The results depict that the total number of confirmed Covid-19 cases in South Sulawesi Province from 19 March 2020 to 18 February 2021 is 53,025 cases with a median (975.5), mean $(2,209.4)$, and variance $(27,977,408)$ which is relatively large. The number of confirmed Covid-19 cases ranged from 206 to 26,658 cases. The results also showed that all localised models with $\mathrm{G}=2, \mathrm{G}=3, \mathrm{G}=4$, and $\mathrm{G}=5$ consisted of more than one group 
indicating the CAR localised model is appropriate. These results are in agreement with previous research (Aswi et al., 2020a, 2020b) stating that the group formed in the localised model is influenced by the magnitude of the mean and variance in the count data between areas. Furthermore, the results showed that the choice of hyperprior in this case study seems to influence the number of areas included in each group.

Based on the preferred model in estimating the relative risk of confirmed Covid-19 cases, it can be concluded that Makassar city has the highest relative risk of confirmed Covid-19 (2.91) followed by Luwu Timur (1.33) and Pare-Pare (1.28), while Toraja Utara has the lowest relative risk of confirmed Covid-19 (0.15) followed by Toraja (0.16). These results are in line with the results of Indonesia SATGAS Covid-19 (SATGAS, 2020) stating that Makassar City was the area with the highest incidence rate followed by Luwu Timur, while Toraja Utara was the area with the lowest incidence rate, followed by Toraja.

Makassar City is an area with the highest population density in South Sulawesi. This allows the transmission of Covid-19 to be very fast. Makassar City is the capital of South Sulawesi Province so that migration is concentrated towards Makassar City. This impact on population mobility can cause the Covid-19 virus to spread rapidly. However, this requires further investigation. Luwu Timur is the second-highest relative risk of confirmed Covid19. This may be due to the fact that Luwu Timur is adjacent to Morowali Utara (Central of Sulawesi) which is categorized as a red zone (high relative risk).

This study has some strengths. To our knowledge, this Bayesian spatial CAR localised model is the first time to model confirmed Covid-19 cases. We explore the first report of a Bayesian spatial CAR localised for modeling the relative risk of confirmed cases of Covid-19 in South Sulawesi Province, Indonesia. This localised model is well supported as it enables the identification of the different groups of areas (areas with the highest relative risk, or low relative risks) as seen in Table 2. This information is worthwhile for the government as it may help officials target healthcare resources and public health interventions to areas that have a high risk of Covid-19. This spatial CAR localised model could be applied in other case studies. This study also compasses the sensitivity analysis. Sensitivity analysis on hyperpriors is important for modeling using the Bayesian method as the choice of hyperprior may influence the posterior probability. However, the prior for the variance term used in this study is still limited to Inverse-Gamma. It is acknowledged that using other priors for the variance hyperparameters such as uniform or half-t priors, may influence the results.

\section{CONCLUSIONS}

In conclusion, the key finding is that the Bayesian spatial CAR localised model is appropriate to model the relative risk of confirmed Covid-19 cases in South Sulawesi Province. The model allows for a distinct group of areas. Particular high-risk areas, as well as low-risk areas, can be detected. Bayesian CAR localised model with $\mathrm{G}=5$ with a hyperprior IG $(1,0.1)$ is the preferred model to estimate the RR in terms of having lower DIC as well as WAIC. This study found that Makassar city has the highest relative risk of confirmed Covid-19 (2.91) This may be due to the fact that Makassar City is the capital of South Sulawesi Province where human mobility is more concentrated in Makassar City. This needs further investigation. On the other hand, Toraja Utara has the lowest relative risk of confirmed Covid-19 (0.15). Including some covariates such as human mobility data, population density, or climatic data, examining other hyperpriors for the variance, comparing other Bayesian 
spatial CAR models, including temporal random effects in the model, could be potential future works.

\section{ACKNOWLEDGMENT}

The authors would like to thank Dr. Susanna Cramb for her valuable suggestions.

\section{REFERENCES}

Annas, S., Isbar Pratama, M., Rifandi, M., Sanusi, W., \& Side, S. (2020). Stability Analysis and Numerical Simulation of SEIR Model for Pandemic COVID-19 Spread in Indonesia. Chaos, solitons and fractals, 139, 1-7. doi:10.1016/j.chaos.2020.110072

Aswi, A., Cramb, S., Duncan, E., \& Mengersen, K. (2020a). Climate Variability and Dengue Fever in Makassar, Indonesia: Bayesian Spatio-temporal Modelling. Spatial and Spatio-temporal Epidemiology, 33, 100335. doi:10.1016/j.sste.2020.100335

Aswi, A., Cramb, S., Duncan, E., \& Mengersen, K. (2020b). Evaluating the Impact of a Small Number of Areas on Spatial Estimation. International Journal of Health Geographics, 19(1), 39-39. doi:10.1186/s12942-020-00233-1

Aswi, A., Cramb, S., Duncan, E., \& Mengersen, K. (2021). Detecting Spatial Autocorrelation for a Small Number of Areas: a Practical Example. Journal of physics. Conference series, 1899(1), 12098. doi:10.1088/1742-6596/1899/1/012098

Aswi, A., Cramb, S. M., Moraga, P., \& Mengersen, K. (2019). Bayesian Spatial and Spatiotemporal Approaches to Modelling Dengue Fever: A Systematic Review. Epidemiology and Infection, 147. doi:10.1017/S0950268818002807

Austin, P. C., Brunner, L. J., SM, H. M., \& Janet, E. (2002). Bayeswatch: An Overview of Bayesian Statistics. Journal of Evaluation in Clinical Practice, 8(2), 277-286.

Badan Pusat Statistik. (2020). Sulawesi Selatan dalam Angka 2020. Retrieved from Makassar:

CNN, I. (2020). Sulsel Jadi Wilayah Kasus Corona Tertinggi di Luar Pulau Jawa. Retrieved from https://www.cnnindonesia.com/nasional/20200407154248-20-491274/sulseljadi-wilayah-kasus-corona-tertinggi-di-luar-pulau-jawa

Congdon, P. (2020). Bayesian Hierarchical models : with Applications using $R$ (Second edition. ed.). Boca Raton, FL: CRC Press.

Dinkes, P. S. S. (2021). Sulsel Tanggap COVID-19. Retrieved from https://covid19.sulselprov.go.id/data

Duncan, E. W., White, N. M., \& Mengersen, K. (2017). Spatial Smoothing in Bayesian Models: A Comparison of Weights Matrix Specifications and Their Impact on Inference (Report). International Journal of Health Geographics, 16(1). doi:10.1186/s12942-017-0120-x

Getis, A., \& Aldstadt, J. (2004). Constructing the Spatial Weights Matrix Using a Local Statistic. Geographical Analysis, 36(2), 90-104. doi:10.1111/j.15384632.2004.tb01127.x

Goldstein, N. D., Wheeler, D. C., Gustafson, P., \& Burstyn, I. (2021). A Bayesian Approach to Improving Spatial Estimates of Prevalence of COVID-19 after Accounting for 
Misclassification Bias in Surveillance Data in Philadelphia, PA. Spatial and Spatiotemporal Epidemiology, 36, 100401-100401. doi:10.1016/j.sste.2021.100401

Konstantinoudis, G., Padellini, T., Bennett, J., Davies, B., Ezzati, M., \& Blangiardo, M. (2021). Long-term Exposure to Air-pollution and COVID-19 Mortality in England: A Hierarchical Spatial Analysis. Environment International, 146, 106316. doi:10.1016/j.envint.2020.106316

Lawson, A. B. (2013). Statistical Methods in Spatial Epidemiology: John Wiley \& Sons.

Lee, D. (2013). CARBayes: An R Package for Bayesian Spatial Modeling with Conditional Autoregressive Priors. Journal of Statistical Software, 55(13), 1-24.

Lee, D., Rushworth, A., \& Sahu, S. K. (2014). A Bayesian Localized Conditional Autoregressive Model for Estimating the Health Effects of Air Pollution. Biometrics, 70(2), 419-429. doi:10.1111/biom.12156

Lee, D., \& Sarran, C. (2015). Controlling for Unmeasured Confounding and Spatial Misalignment in Long-term air Pollution and Health Studies. Environmetrics, 26(7), 477-487.

Moran, P. A. P. (1950). Notes on Continuous Stochastic Phenomena. Biometrika, 37(1-2), 17. doi:10.1093/biomet/37.1-2.17

Oyana, T. J., \& Margai, F. (2015). Spatial Analysis: Statistics, Visualization, and Computational Methods Boca Raton: CRC Press.

R Core Team. (2019). R: A Language and Environment for Statistical Computing. Vienna, Austria: R Foundation for Statistical Computing. Retrieved from http://www.Rproject.org

Samer, A. K. (2020). Modeling the Spread of COVID-19 in Lebanon: A Bayesian Perspective. Frontiers in Applied Mathematics and Statistics, 6. doi:10.3389/fams.2020.00040

SATGAS, P. C.-. (2020). Analisis Data COVID-19 di Indonesia.

Shereen, M. A., Khan, S., Kazmi, A., Bashir, N., \& Siddique, R. (2020). COVID-19 Infection: Origin, Transmission, and Characteristics of Human Coronaviruses. Journal of Advanced Research, 24, 91-98. doi:10.1016/j.jare.2020.03.005

Sifriyani, S., \& Dedi, R. (2020). Susceptible Infected Recovered (SIR) Model for Estimating Covid-19 Reproduction Number In East Kalimantan And Samarinda. Media Statistika, 13, 170-181. doi:10.14710/medstat.13.2.170-181

Spiegelhalter, D. J., Best, N. G., Carlin, B. P., \& Van Der Linde, A. (2002). Bayesian Measures of Model Complexity and Fit. Journal of the Royal Statistical Society: Series B (Statistical Methodology), 64(4), 583-639.

Vehtari, A., Gelman, A., \& Gabry, J. (2017). Practical Bayesian Model Evaluation using Leave-one-out Cross-validation and WAIC. Statistics and Computing, 27(5), 14131432. doi:10.1007/s11222-016-9696-4

Watanabe, S. (2010). Asymptotic Equivalence of Bayes Cross Validation and Widely Applicable Information Criterion in Singular Learning Theory. Journal of Machine Learning Research, 11, 3571-3594. 
WHO. (2021). Weekly Epidemiological and Weekly Operational Updates February 2021. Retrieved from https://www.who.int/publications/m/item/weekly-epidemiologicalupdate---16-february-2021

Yeni, Najmah, \& Davies, S. G. (2020). Predicitive Modeling, Empowering Women, and COVID-19 in South Sumatra, Indonesia. ASEAN Journal of Community Engagement, 4(1), 104-133. doi:10.7454/ajce.v4i1.1094

Zuhairoh, F., \& Rosadi, D. (2020). Real-time Forecasting of the COVID-19 Epidemic using the Richards Model in South Sulawesi, Indonesia. Indonesian Journal of Science \& Technology, 5(3), 456-462. doi: https://doi.org/10.17509/ijost.v5i3.26

\section{Supplementary table Table S1}

The number of confirmed Covid-19 cases, the number of population, and population density for every district.

\begin{tabular}{lccc}
\hline Districts/City & $\begin{array}{c}\text { Number of Confirmed } \\
\text { Covid-19 Cases }\end{array}$ & Population & $\begin{array}{c}\text { Population Density } \\
\text { per km seq }\end{array}$ \\
\hline Barru & 788 & 174323 & 148 \\
Bone & 1270 & 758589 & 166 \\
Bulukumba & 750 & 420603 & 364 \\
Enrekang & 289 & 206387 & 116 \\
Gowa & 4790 & 772684 & 410 \\
Jeneponto & 1406 & 363792 & 403 \\
Luwu Timur & 2401 & 299673 & 43 \\
Luwu Utara & 1200 & 312883 & 42 \\
Luwu & 592 & 362027 & 121 \\
Makassar & 26658 & 1526677 & 8686 \\
Maros & 1975 & 353121 & 218 \\
Palopo & 1238 & 184614 & 746 \\
Pangkep & 1202 & 335514 & 302 \\
Pare-Pare & 1121 & 145178 & 1462 \\
Pinrang & 839 & 377119 & 192 \\
Selayar & 441 & 135624 & 150 \\
Sidrap & 881 & 301972 & 160 \\
Sinjai & 1307 & 244125 & 298 \\
Soppeng & 980 & 226991 & 167 \\
Takalar & 969 & 298688 & 527 \\
Toraja Utara & 206 & 231214 & 201 \\
Toraja & 228 & 234002 & 114 \\
Wajo & 755 & 397814 & 159 \\
Bantaeng & 739 & 187626 & 474 \\
\hline & & &
\end{tabular}

